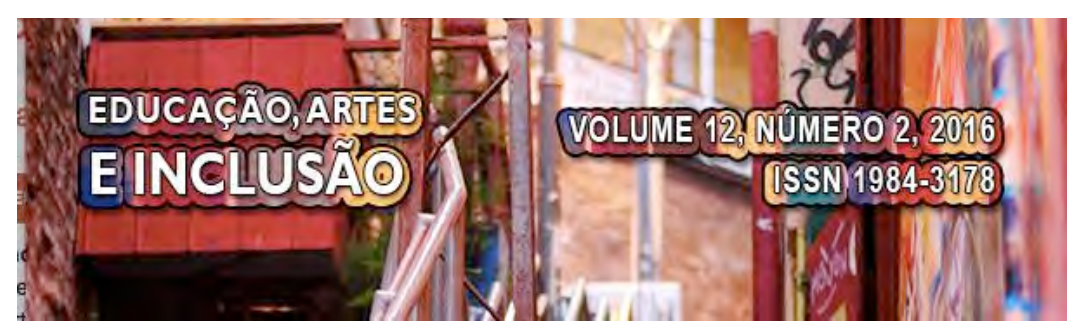

\title{
O PROFESSOR NO CINEMA ESTADUNIDENSE: MODELOS DE PROFISSIONAIS E IDEOLOGIAS
}

\section{TEACHER IN THE CINEMA: PROFESSIONAL MODELS AND IDEOLOGIES}

DOI: http://dx.doi.org/10.5965/1984317812022016073

Vania Cristina Pauluk Cavalheiro - UEPG

\section{RESUMO}

Este artigo é resultado de estudos e pesquisa da Pós-graduação- Especialização em Mídia, Política e Atores Sociais, na Universidade Estadual de Ponta Grossa. Este texto busca analisar e discutir o perfil do profissional professor veiculado em filmes de grande sucesso produzidos pela indústria cinematográfica estadunidense. Procurou-se analisar como a constituição dos personagens (professores) encontra-se consoante com os ideários neoliberais em educação e a presença dessas ideologias no enredo. Os filmes selecionados são aqueles de fácil acesso pela população: exibidos por redes de televisão em canais abertos e lançados em cinema. Outro critério seguido na seleção buscou filmes foi que os personagens principais fossem representados por atores de grande sucesso midiático. Em todos os filmes há a presença desses atores, como é o caso de: Cameron Diaz e Hilary Swank. Os filmes selecionados são todos produzidos nos Estados Unidos e os enredos retratam especialmente a história de um professor, ou seja, o enredo se dá por meio da história profissional/pessoal desse sujeito. Verificou-se a forte presença das ideologias neoliberais em educação nos filmes analisados.

Palavras-chave: neoliberalismo, cinema estadunidense, ideologia, professor

\begin{abstract}
This article is a result studies of and investigates of postgraduate-Specialization in Media, Politics and Social Actors" in the State University of Ponta Grossa. This paper analyses the profile of the teacher conveyed in movies of great sucess produced by the North American cinematographic industry. It was analysed like the constitution of the characters (teacher) consonant meets with the neoliberal ideals in education and the presence of these ideologies in the plot. The selected movies are those easy to get to for the population: shown by television and in cinema. Another criterion followed in the selection looked for movies was that the main characters were represented by actors of great success. In all the movies there is the presence of these actors, as: Cameron Diaz and Hilary Swank. The selected movies are all produced in the United States and the plots show specially the history of a teacher, in other words, the plot happens through the professional history / personal of this subject. There are a strong presence of the neoliberal ideologies in education in the analysed movies.
\end{abstract}

Keywords: neoliberalism, North American cinema, ideology, teacher 


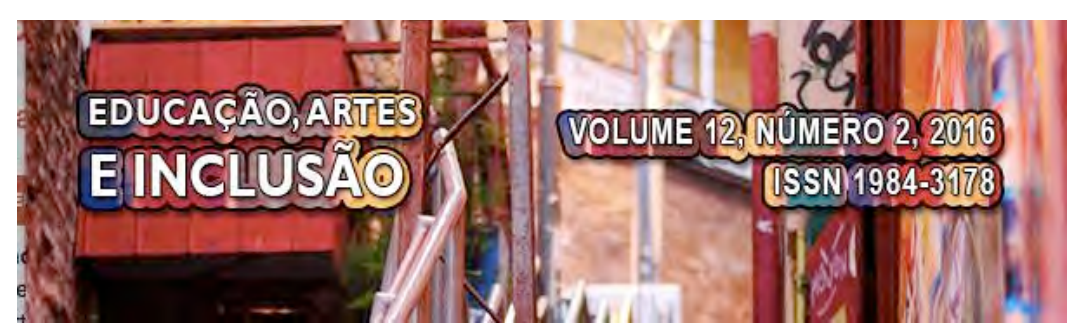

\section{INTRODUÇÃO}

As figuras da escola e do professor fazem parte da vida da maioria das pessoas. Ver nas telas de cinema ou televisão recortes da realidade escolar interessa a muitos sujeitos. É comum ver o cotidiano escolar ser retratado em filmes, documentários e desenhos, etc.

Considerando a inexistência de neutralidade. E, também tendo em vista que todos os produtos culturais estão repletos de valores e ideologias, nos propomos a analisar as ideologias que podem estar presentes na caracterização dos personagens/professores e no coletivo escolar vinculadas nos filmes. De acordo com Kellner os produtos das indústrias culturais apresentam a função específica "de legitimar ideologicamente as sociedades capitalistas existentes e de integrar os indivíduos nos quadros da cultura de massa e da sociedade", (2001, p.44).

Pode-se considerar que as ideologias e valores existentes nesses filmes podem colaborar para uma visão de educação que não está conformidade com os interesses das classes trabalhadoras. Pois, apregoam a meritocracia, a não intervenção do Estado na educação e o voluntariado para solucionar os problemas educacionais, entre outros.

\section{NEOLIBERALISMO}

As bases do liberalismo econômico foram propostas por Adam Smith, no século XVIII, as quais incluíam as seguintes ideias: liberdade de comércio e indústria, o trabalho humano como verdadeira fonte de riqueza e a não intervenção do Estado na economia. $\mathrm{O}$ neoliberalismo é o novo liberalismo e conserva essas características. Sendo um conjunto particular de receitas econômicas e programas políticos que começaram a ser propostos nos anos 1970, em especial, por Ronald Reagan nos Estados Unidos e Margaret Thatcher, no Reino Unido.

A nova ordem mundial definida pelos organismos internacionais, tais como Fundo Monetário Nacional (FMI), Banco Interamericano de Desenvolvimento (BID), Banco Mundial, entre outros, propôs um novo papel ao Estado, mantendo sua estrutura de coerção, mas desarticulando suas funções sociais. Esses organismos internacionais de financiamento impõem aos países em desenvolvimento; os quais têm grande dívida externa; medidas de 


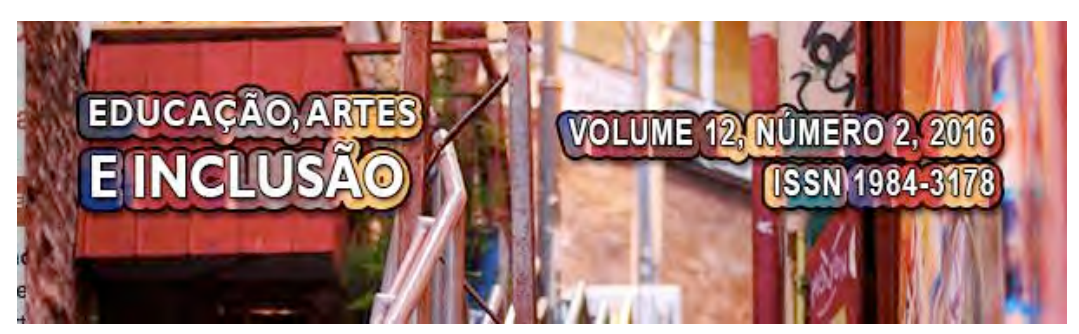

ajuste econômico, aprovadas no denominado "Consenso de Washington", realizado em novembro de 1989, (e os citados países se submetem aceitando os ajustes a fim de conseguir refinanciamento). Suas recomendações abrangem algumas áreas, são elas: "disciplina fiscal, priorização de gastos públicos, reforma tributária, liberalização financeira, regime cambial, liberalização comercial, investimento direto estrangeiro, privatização, desregulação e propriedade intelectual" (CARCANHOLO, 2000, p.25).

No Brasil o ideário neoliberal começou a ser proposto pelo então presidente Fernando Collor de Mello. Ele usou como um dos slogans para sua reforma: "Caça aos Marajás”. Os serviços públicos foram demonizados com ênfase na ideia de que os mesmos não têm qualidade e são prestados por servidores ineficientes. Também incentivou-se um programa de demissão voluntária de funcionários públicos. Foi realizado cancelamento e/ou redução de pensões e/ou privilégios.

Essas políticas se basearam no ideário liberal que apregoa o Estado Mínimo para o cidadão. Esse ideário prega também a não intervenção do Estado na economia, afirmando que através da competição haverá melhores produtos e preços ao consumidor. Uma mão invisível a qual regulará o mercado. Percebe-se, no entanto, a falácia desse discurso, pois, o Estado mostra-se forte para o mercado, nas crises que são produzidas/geradas no sistema capitalista, auxiliando-o financeira e politicamente nessas crises.

Os países ditos desenvolvidos procuram proteger seus mercados por meio de subsídios, colocando barreiras tributárias a produtos estrangeiros e utilizam o pretexto de baixa qualidade para evitar sua importação. Os Estados periféricos foram pressionados a abrir seus mercados. Contudo, a "mão invisível que regularia o mercado" não existe, pois há constantemente a formação de fusões e de blocos econômicos.

As medidas neoliberais não têm surtido o efeito prometido nos discursos. As desigualdades se intensificaram nos países pobres, resultando no novo fenômeno: a pauperização do pobre. O neoliberalismo impôs uma feroz disciplina fiscal com bons resultados no controle da inflação, mas pauperizou as massas, o que é inaceitável. Produziu um retrocesso social agravando as desigualdades. Crescimento econômico não é sinônimo de divisão de rendas e diminuição de desigualdades. "Defendemos uma concepção política nos marcos da qual a intervenção estatal deve efetivamente se basear na solidariedade social, ou 


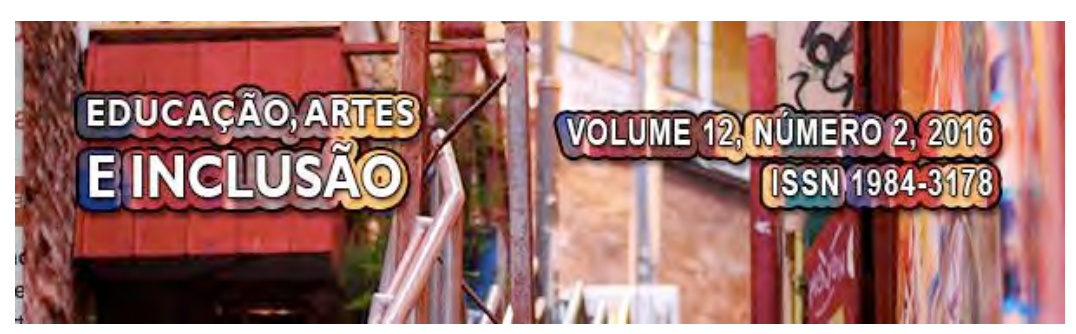

seja, na diminuição das desigualdades e não somente na eficácia econômica”, (SADER e GENTILI, 1995, p. 143).

\subsection{NEOLIBERALISMO E EDUCAÇÃO}

O ideário neoliberal no plano político, instaura a lógica do Estado Mínimo, da desregulação e privatização da esfera pública. No campo educacional, segue a mesma lógica de redução de gastos com o público, incentivo ao ensino privado e tecnológico. $\mathrm{O}$ neoliberalismo utiliza um duro ajuste econômico para a diminuição de gastos do Estado, desmanchando as políticas sociais e os serviços públicos. A participação da comunidade é incentivada para substituir e ocupar o lugar mantenedor do Estado.

$\mathrm{Na}$ concepção neoliberal a educação escolar deixa de ser vista como direito do cidadão, e passa a ser atribuída a ela a função de preparação de mão de obra ao mercado. Há o ressurgimento da teoria do capital humano, concepção a qual conforme Frigotto (1999 e 2001): coloca a educação como potencializadora de trabalho e renda e restringe seu papel à preparação de mão de obra ao sistema capitalista.

Uma nova visão de desenvolvimento, ciência e tecnologia demandam ajustes à educação para que adeque a formação profissional à reestruturação produtiva. As mudanças ocorridas no processo de produção, ou seja, a mudança dos métodos rígidos para os flexíveis demanda ao mercado um novo tipo de trabalhador. O mercado de trabalho, anteriormente, necessitava de um trabalhador com boa coordenação motora e acuidade visual, para o exercício de atividades mecânicas e repetitivas, no modelo taylorista/fordista, (KUENZER, 2003).

Por meio da globalização econômica, cultural e política somos integrados a partir de uma reestruturação internacional, onde nos cabe o modelo toyotista nas relações de produção. Nosso modelo educacional procura ajustar-se a esse modelo. As competências necessárias ao trabalhador para manter sua empregabilidade são aquelas que aumentam sua produtividade. “O capital agora se interessa não só pela força física, mas também pelas qualidades intelectuais, emocionais e afetivas". (FERREIRA e OLIVEIRA, 2009, p. 68)

Neste novo processo de produção não há espaço para um trabalhador desqualificado e 


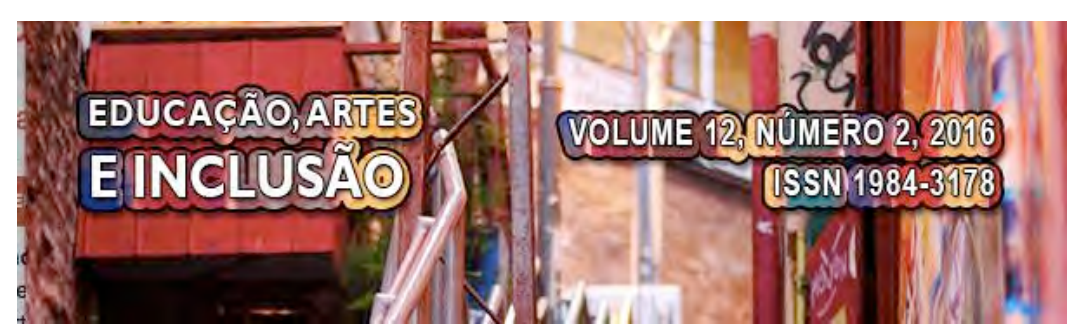

incapaz de assimilar novas tecnologias. Para Ferreira e Oliveira "a desqualificação passou a significar exclusão no novo sistema produtivo, realçando a exigência de um trabalhador cada vez mais qualificado, polivalente e flexível, num processo contínuo de aprendizagem, em que se pese o declínio dos postos de trabalho ou chamado desemprego estrutural" (2009, p. 240).

No contexto produtivo desapareceria a tendência de profissionalização do trabalhador, haja vista a eminente necessidade de polivalência. $O$ mundo de trabalho, inspirado no modelo toyotista, exige profissionais com outras habilidades, entre as quais se destaca: criatividade, iniciativa, capacidade de trabalhar em grupo, propor soluções, criticar, entre outros, (SAVIANI, 2007). No entanto, para atingir aos objetivos mercadológicos, não se faz suficiente uma escola que se baseie em atividades mecânicas e repetitivas. É necessária uma formação visando a polivalência, a qual pode ser entendida como a "ampliação da capacidade do trabalhador para aplicar novas tecnologias, sem que haja mudança qualitativa desta capacidade" (KUENZER, 2003, p. 11).

Vale ressaltar que, a polivalência ao superar a fragmentação do conhecimento difere da politecnia, pois, busca o domínio intelectual da técnica e a superação da fragmentação do conhecimento. Sem necessidade de se dominar a totalidade, mas de conhecer a relação entre as partes, visando o desenvolvimento de tarefas com criatividade, crítica e autonomia pessoal e ética.

Vive-se uma contradição mundial, na qual de um lado há demanda por maior qualificação, demandando uma mão de obra mais flexível, afastando-se do padrão taylorista/fordista. E, por outro lado, restringe o acesso aos postos de trabalho, aumentando a precarização do trabalho, numa lógica educacional mercadológica, de formação e adestramento de mão de obra ao mercado uma vez que se encontra

morta definitivamente a promessa do pleno emprego, restará ao indivíduo (e não ao Estado, às instâncias de planejamento ou às empresas) definir suas próprias opções, suas próprias escolhas que permitem (ou não) conquistar uma posição mais competitiva no mercado de trabalho. A desintegração da promessa integradora deixará lugar à difusão de uma nova promessa, agora sim, de caráter estritamente privado: a promessa de empregabilidade. (FRIGOTTO, 2008, p. 81, grifos do autor). 


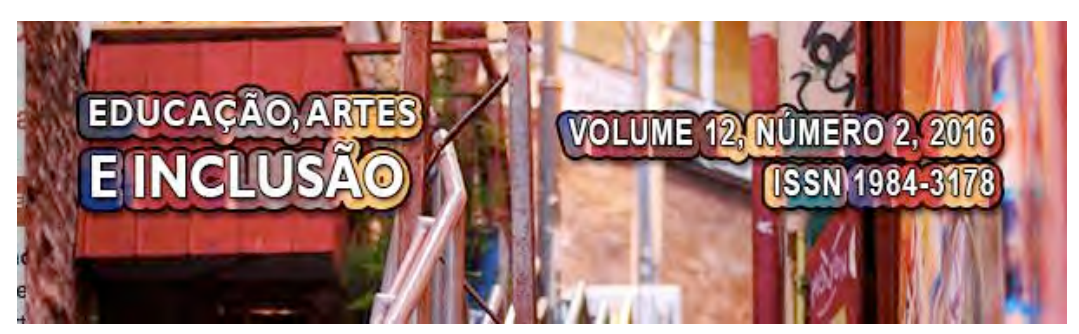

Conforme a lógica neoliberal meritocrática, a culpa pelo não ingresso ou permanência no dito mundo de trabalho é apenas do trabalhador, por não ter as habilidades e competências necessárias e não ter se esforçado para adquiri-las.

O fundo público, para essa ofensiva deve garantir um patamar mínimo de escolaridade ou subsídio aos mais pobres, se constituindo como quer o Banco Mundial como um alívio à pobreza. De acordo com tal projeto social os indivíduos devem adquirir competências ou habilidades no campo cognitivo, técnico, criatividade, autonomia, para tornaram-se empregáveis e competitivos. No cenário nacional “a educação básica tem se deteriorado nas últimas décadas, e por tradição, a formação técnico-profissional tem sido decidida no campo técnico-empresarial, o mercado", de acordo com Frigotto, (2008, p.106)

Neste sentido, vislumbra-se no Brasil a proliferação das instituições de ensino superior privadas, com financiamento público via FIES e PROUNI, na lógica mercadológica, onde nem sempre se preza pela qualidade social da educação, mas prioriza-se o que Acácia Kuenzer chama de certificação vazia. Há o crescimento da oferta de ensino técnico, em especial, utilizando-se para tal o Sistema S, por meio do PRONATEC, o que pode aprofundar o dualismo educacional, por nem sempre ter como objetivo a politecnia, mas, sim a polivalênica.

São incentivados em diretrizes e parâmetros curriculares, os ditos pilares da educação, a saber: "aprender a aprender", “aprender a conhecer”, “aprender a fazer”, “aprender a ser”, "aprender a viver junto", propondo uma educação para toda a vida numa "sociedade aprendente". Conceitos esses presentes no cenário internacional e integrantes do Relatório Jacques Delors (apoiado e promovido pela Unesco- Organização das Nações Unidas para a Educação, a Ciência e a Cultura). Em documentos de organismos internacionais, fica explícito o tipo de educação que deve ser destinada às classes trabalhadoras e os objetivos da mesma. Ou seja, fica explícito o menosprezo pelo conhecimento científico e o incentivo a adquirir habilidades e competências, para as classes trabalhadoras para atuarem no mercado de trabalho. Sendo-lhes destinado mínino de conhecimento necessário para o exercício de suas funções.

O Banco Mundial financia projetos educacionais (com altos juros) com o discurso de 


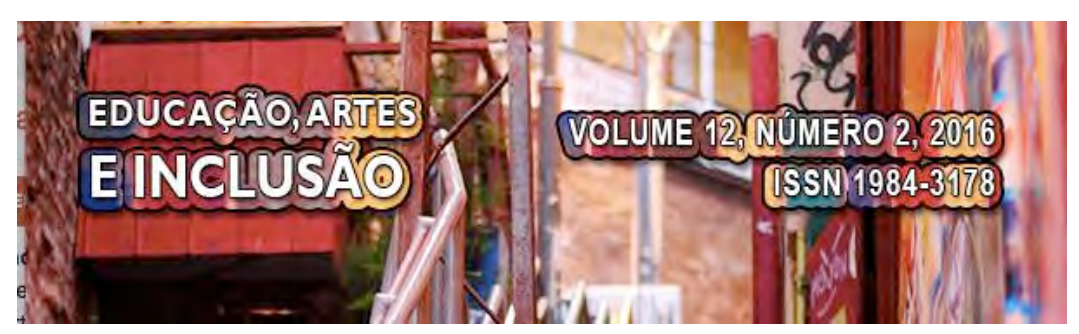

ajudar na reduzição da pobreza: aumentando a produtividade do trabalho dos pobres, redução da fecundidade e dotando as pessoas com atitudes para participar plenamente na economia e na sociedade (SHIROMA, 2007).

Há que se considerar outra contradição existente na realidade educacional brasileira, na qual muitos alunos passam pelos bancos escolares, sendo de certa forma incluídos no sistema educacional, mas saem dele sem terem se apropriado dos conhecimentos relativos às séries cursadas, o que Kuenzer chama de inclusão excludente, ou seja:

estratégias de inclusão nos diversos níveis e modalidades da educação escolar aos quais não correspondam os necessários padrões de qualidade que permitam a formação de identidades autônomas intelectual e eticamente, capazes de responder e superar as demandas do capitalismo; ou, na linguagem toyotista, homens e mulheres flexíveis, capazes de resolver problemas novos com rapidez e eficiência, acompanhando as mudanças e educando-se permanentemente. Estas estratégias têm sido várias, mas merecem destaque as que temos chamado de "empurroterapia", as quais têm decorrido de uma distorcida apropriação de processos desenvolvidos no campo da esquerda para minimizar os efeitos da precarização cultural decorrente da precarização econômica, com a única preocupação de melhorar as estatísticas educacionais: ciclagem, aceleração de fluxo, progressão automática, classes de aceleração, e assim por diante. É importante destacar que estas estratégias, se adequadamente implementadas, favorecem a democratização das oportunidades educacionais. (2010, p.14-15)

Sendo assim, muitos passam longos anos nos bancos escolares e saem sem o mínimo necessário para ingresso no mundo de trabalho e inserção social consciente e criativa. Essa inclusão não serve nem ao menos aos objetivos mercadológicos, muito menos aos objetivos maiores da educação para a classe trabalhadora. Concordamos com Saviani (2007, p. 160) ao afirmar que:

O nível de desenvolvimento atingido pela sociedade contemporânea coloca a exigência de um acervo mínimo de conhecimentos sistemáticos, sem o que não se pode ser cidadão, isto é, não se pode participar ativamente da vida da sociedade. (...) Aprender a ler, escrever e contar, e dominar os rudimentos das ciências naturais e das ciências sociais constituem pré-requisitos para compreender o mundo em que se vive, inclusive para entender a própria 


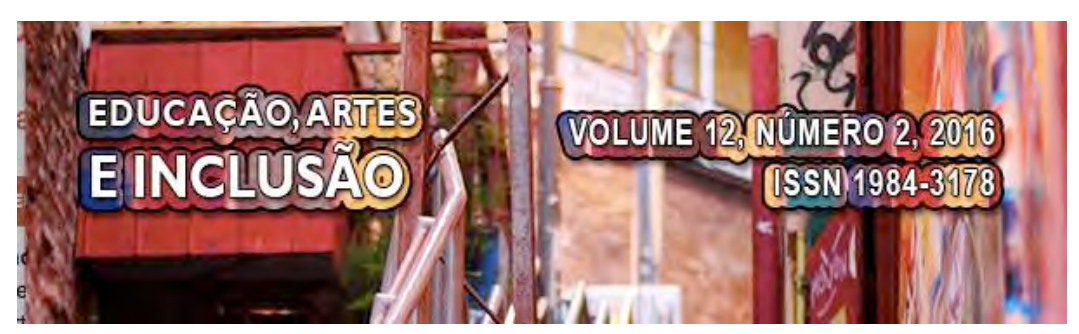

O cinema, dentro desta perspectiva, atinge a muitos telespectadores de diferentes culturas, mas cada telespectador pode inferir ao texto filme uma diversidade de significados e sentidos, dependendo de sua visão de homem/ mundo.

Em seus enredos há muitos conteúdos tanto explícitos como implícitos. O cinema pode ser caracterizado como um objeto de conhecimento, os conteúdos por ele abordados fornecem revelações sobre a construção do universo da informação. Há filmes que retratam conceitos e situações históricas, documentários que expressam conhecimentos e informações sobre determinados temas. Podemos considerar que há filmes, os quais sem ter especificamente essa intencionalidade acabam expressando valores e modos de vida, os quais são transmitidos por meio de seu enredo, música, constituição dos personagens, entre outros.

O cinema, historicamente foi projetado para ser de certa forma elitizado, de acordo com Pecari (1995). As salas de música, teatro, cinema foram projetadas para um público limitado, não sendo suficientes para atender a demanda de consumo da grande massa. De acordo com esse autor, a televisão que se destina ao dito "gosto popular", atingindo um maior número de pessoas. No entanto, entendemos que com a globalização e o avanço científico e tecnológico, o cinema chega a atingir a massa, quer de maneira legal, em salas de cinema, espalhadas em shoppings ou outros locais, quer de modo ilegal, com a pirataria ou acesso facilitado em sites da internet.

Na década de 1950 a indústria cinematográfica enfrentou desafios com o avanço da televisão nos lares estadunidenses. Inicialmente, os estúdios tentaram deter a veiculação de filmes na televisão, mas sem êxito passaram a utilizá-la como um importante aliado, tanta na liberação da transmissão de filmes, como na produção de filmes e programas para a televisão. Nem sempre a indústria cinematográfica consegue sobreviver sem que suas obras sejam postas na televisão.

As novas tecnologias têm impacto sobre esse mercado e cabe a ele repensar como utilizá-las para seu lucro. O caso das fitas de videocassete é um exemplo do exposto: em 1998 representavam um negócio de 17 bilhões de dólares. Em apenas duas semanas de exibição em domicílios estadunidenses atingiam $40 \%$ do público que os cinemas demoravam um ano para atingir, (DIZARD, 2000). 


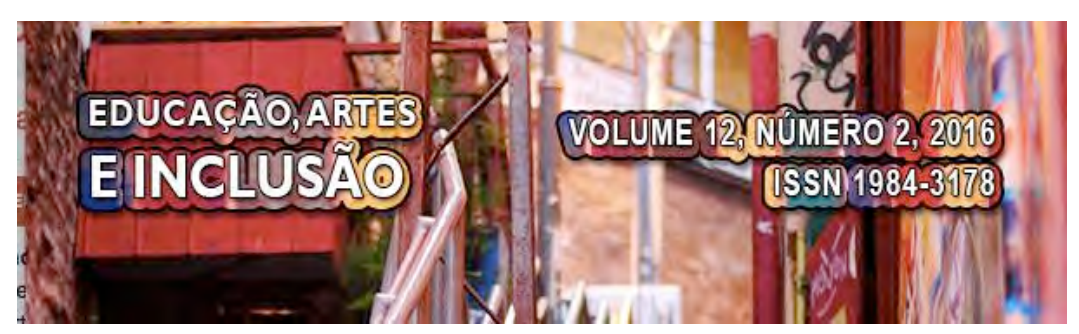

A indústria cinematográfica tem renovado seus produtos, usando diferentes ferramentas para atrair cada vez um número maior de público, aumentando o número de filmes feitos por computação e com grandes efeitos especiais que disputam a fama com grandes atores. A indústria cinematográfica dos Estados Unidos, não se restringe a Hollywood, há tempos transferiu suas produções para outras regiões de Los Angeles. No entanto, este termo serve para significar essa indústria cinematográfica como guia do entretenimento.

As produções cinematográficas que são sucessos artísticos, nem sempre são sucessos comerciais. Para Dizard “as tensões entre economia da linha dura e a criatividade artística são mais evidentes da indústria cinematográfica do que qualquer outro setor da mídia” (2000, p. 192). De cada dez filmes produzidos em Hollywood seis dão prejuízo financeiro. O sucesso de grandes bilheterias vai equilibrar esse negócio. Assim como a venda de produtos relacionados aos filmes, como exemplo no caso dos desenhos da Disney, os quais exploram diferentes objetos, parques temáticos, entre outros.

Grande parte dos estúdios faz parte de grandes corporações, ocorrendo muitas fusões entre tais empresas formando-se conglomerados de mídia, verifica-se que: "além de uma vasta produção de filmes altamente comerciais para uso exclusivo da televisão, assistimos a uma produção de filmes de grande valor artístico, mas que parecem precisar viver fora da TV o menor tempo possível para os produtores não terem prejuízo econômico" (PICCARDI, 1995, p. 63).

O atrativo estético é inerente ao filme produzido para o cinema. Mesmo muitos produtores tendo como prioridade a realização artística ao produzir um filme, não há como negar o imperativo comercial da produção cinematográfica. Nem sempre se prioriza a educação para a sensibilidade estética, mas sim os valores mercadológicos. $\mathrm{O}$ ato de assistir a um filme em um cinema é uma escolha do sujeito que a realiza conforme critérios subjetivos.

Entre as propostas de leitura e análise de filmes, geralmente, se contempla os seguintes aspectos, a saber: a análise estética, análise de conteúdo e juízo artístico. A análise estética se concentra no estímulo estético ou no nível de encantamento, verificando os seguintes aspectos: "vivenciando a intuição criadora do artista e projetando a percepção estética da obra que vai além da espontânea intuição de beleza”. A crítica artística ou análise crítica do 


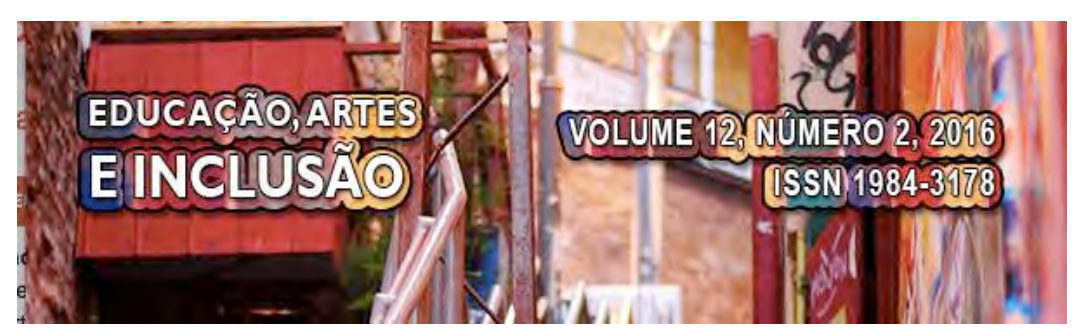

conteúdo que pode ser entendida como "o momento lírico de encantamento antes que a mente emita um conceito" (PICCARDI, 1995, p. 65). E também é importante considerar que,

um estudo cultural crítico e multicultural deve, portanto, levar a cabo uma crítica das abstrações, das reificadas e dessas fronteiras até suas origens sociais, criticando distorções, mistificações e falsificações aí presentes. Uma das funções da cultura da mídia dominante é conservar fronteiras e legitimar o domínio da classe, da raça, e do sexo hegemônico, de acordo com Kellner (2001, p. 85).

Contudo, faz-se necessário realizar a reflexão, discussão e problematização das ideologias que representam visões racistas, sexistas. Assim como qualquer tipo de preconceito que podem ser são postos como forma de sustentação teórica na dominação.

\section{AGENDAMENTO DE IDEOLOGIAS NO CINEMA E FORMAÇÃO DE OPINIÃO PÚBLICA}

Todas as sociedades possuem marcas de uma cultura e certas apresentam a tendência de impor sua cultura através de classificações do mundo social, cultural e político. A cultura constitui uma ordem social dominante, mesmo não sendo nem unívoca, nem incontestável. A cultura é entendida como um meio de identificação dos sujeitos e permite que esses tenham suas ações direcionadas para sentirem-se pertencentes a um determinado grupo, agindo segundo as normas determinadas pelo mesmo, mas, não há uma reprodução idêntica de hábitos.

As culturas sempre estão em contato e estabelecem uma relação de troca umas com as outras. Os produtos culturais são levados a expandirem se continuamente em diferentes mercados, sendo nada mais do que uma cultura-tradição difundida pelo mundo todo pela indústria, estando as tecnologias de comunicação envolvidas, pois são elas que engendram processos diferenciados de produção de sentidos. O conceito de cultura, nesse sentido, está intimamente relacionado com as relações de poder, como também há conexões entre cultura, contexto, as relações e as determinações sociais. 


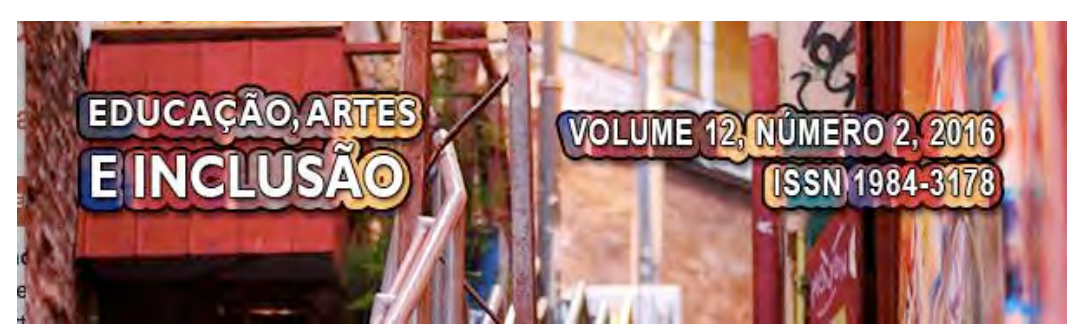

A aceleração do processo circulatório dos produtos culturais, a fusão das indústrias setoriais gerando poderosos conglomerados que dominam o mercado mundial, são exemplos de como a indústria cultural vai sendo construída no cenário neoliberal. A venda de produtos técnicos não se reduz apenas aos produtos, mas ao modo de vida e valores que dele se originam: "o capitalismo cria sem querer as condições para uma democratização da cultura, ao tornar os bens culturais objeto de produção industrial” explica Rüdiger, (2003, p. 135).

A presença de elementos da cultura estadunidense no mundo é considerável; na língua, produtos, grandes indústrias, e também dos filmes, os quais representam uma parcela substancial de seu lucro.

O constante fascínio do mundo pelos filmes americanos é tal que Hollywood tornou-se o maior contribuinte do comércio americano nas exportações da mídia. Os filmes americanos são responsáveis por cerca de $15 \%$ da produção anual, (...) os filmes americanos dominam a lista de filmes populares mais vistos no exterior. Muitos filmes americanos têm sucesso financeiro maior que no exterior do que no mercado interno, (DIZARD, 2000, p. 211).

O cinema estadunidense não exporta apenas filmes, mas elementos de sua cultura, ideologias e valores. Com a utilização de novas tecnologias, os modos de vida e valores são mais, facilmente, exportados.

As novas tecnologias introduzem elementos de tempo real e espaço virtual, antecipando acontecimentos. A sociedade contemporânea rege-se pela midiatização. De acordo com Sodré (2002) o indivíduo é posto para relacionar-se num horizonte comunicacional de interatividade absoluta ou conectividade permanente, sendo a midiatização um novo modo de inserção do sujeito no mundo.

A globalização faz com que uma situação específica ocorrida em um dado território afete moradores de distantes e diferentes lugares. Como exemplo, pode-se citar as crises econômicas nos Estados Unidos e Europa que afetaram e ainda afetam outros países. O mundo preocupa-se com uma crise na China, na Europa ou nos Estados Unidos. Os produtos culturais: cantores, artistas, filmes, programas de televisão, etc., lançados em um país também são difundidos para muitos outros. 


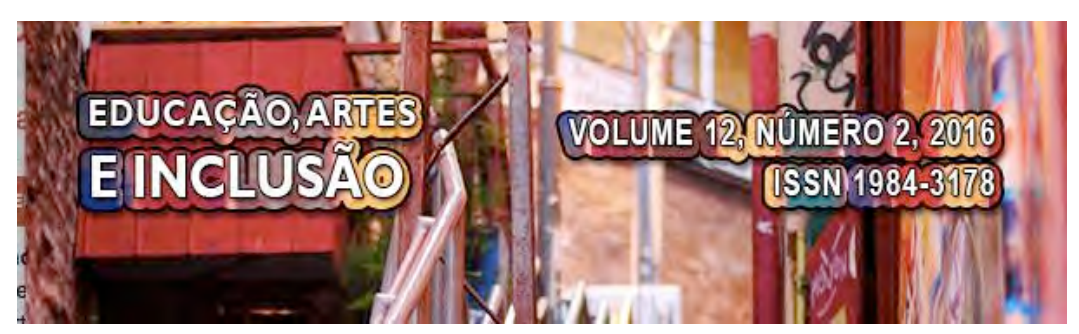

O capitalismo aparece como um processo civilizatório, universal e autoritário, impondo-se às formas sociais de vida e trabalho. Os valores incentivados são os do capital, onde se verifica uma “incansável e insaciável demanda de crescimento e progresso; sua expansão dos desejos humanos para além das fronteiras locais, nacionais e morais", conforme Berman, (2003, p.138). Os sujeitos têm a impressão de pertencerem ao mundo, ou seja, são cidadãos do mundo.

No mundo contemporâneo é difícil caracterizar e identificar identidades nacionais, pois, para o capital globalizado as identidades particulares são dissolvidas, o que menos têm relevância e para a definição da identidade é o local de nascimento do cidadão. De acordo com Ianni, "a formação da sociedade global modifica substancialmente as condições de vida e trabalho, os modos de ser, sentir, pensar e imaginar", (1999, p. 50).

O circuito de transmissão e/ou difusão de cultura é representado por instâncias de produção, circulação e consumo. Essas instâncias podem ocorrer em diferentes momentos e localidades. É preciso ressaltar que toda a mídia pode ser entendida como expressão da cultura. Para Kellner é importante considerar que:

a mídia colonizou a cultura, que ela constituiu o principal veículo de distribuição e disseminação da cultura, que os meios de comunicação de massa suplantaram os modos anteriores de cultura como o livro ou a palavra falada, que vivemos num mundo no qual a mídia domina o lazer e a cultura. Ela é, portanto, a forma dominante e o lugar da cultura nas sociedades contemporâneas, (2001, p. 54).

\section{A ESCOLA, O PROFESSOR E O CINEMA}

A escola e o professor são muito retratados no cinema, mesmo porque essas figuras fazem parte da vida de quase todos os sujeitos. As histórias de vida dos personagens representados nos filmes, podem permitir: a identificação do público com esses personagens ou com suas histórias, a reflexão e/ou crítica dos papéis por ele assumidos, a assimilação de valores e ideologias, entre outros. De acordo com Calles, (2012, p. 70) o filme é um:

importante veículo de representações e imaginário social em virtude da impressão de realidade: processo afetivo e perceptivo de participação, ar de realidade e credibilidade. Diante do filme "o expectador se expõe à identificação ou contraposição de valores, modos de viver, agir e pensar". 


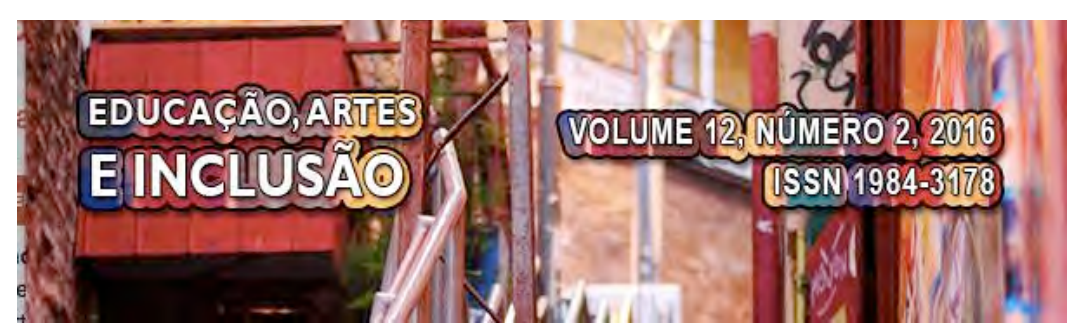

adaptam às necessidades dos seus alunos (CALLES, 2012, p. 80). Isso é visto em: Sorriso de Monalisa, Escritores da liberdade, Mentes Perigosas, A creche do Papai, entre outros.

O sujeito caracterizado como bom professor, nestes filmes, consegue o respeito, a afeição e a disciplina dos alunos. Assim como tem sucesso em gerir diferentes tipos de conflitos e interagir de forma firme, eficaz e cordial. Nesses filmes predominam a reprodução de clichês e um imaginário social sobre a profissão docente. É recorrente a representação da figura heroica do professor, enfrentando muitos desafios e inclusive usando seus recursos financeiros para melhorar a qualidade de educação.

Os filmes, em geral se apresentam com narrativas de estrutura clássica. Esses filmes são um produto de massa a ser consumido na sociedade capitalista. Essa indústria, como já afirmado, não vende/exporta apenas esses produtos, mas difunde nesse mundo global a ideário neoliberal. Há sempre a necessidade de análise crítica a respeito das representações, conceitos, valores, perspectivas inclusos nestes produtos culturais, haja vista que os filmes são "artefatos culturais profundamente identificados com a cultura que os produziu e, pelos significados que adquirem nos espaços em que circulam", de acordo com Pinheiro, (2012, p. 73).

\section{IDEOLOGIAS NEOLIBERAIS EM FILMES HOLLYWODIANOS}

Nesta parte do texto realizar-se-á a análise e discussão de ideologias neoliberais presentes em filmes estadunidenses, os quais caracterizam o profissional professor e seu papel na sociedade. Isto posto, entende-se ideologia como as ideais e representações das classes dominantes difundidas para legitimar e assegurar o poder político e econômico. De acordo com Chauí:

a ideologia consiste precisamente na transformação das idéias da classe dominante em idéias dominantes para a sociedade como um todo, de modo de que a classe que domina no plano material (econômico, social e político) também domina no plano espiritual (das idéias). (2006, p. 85) 


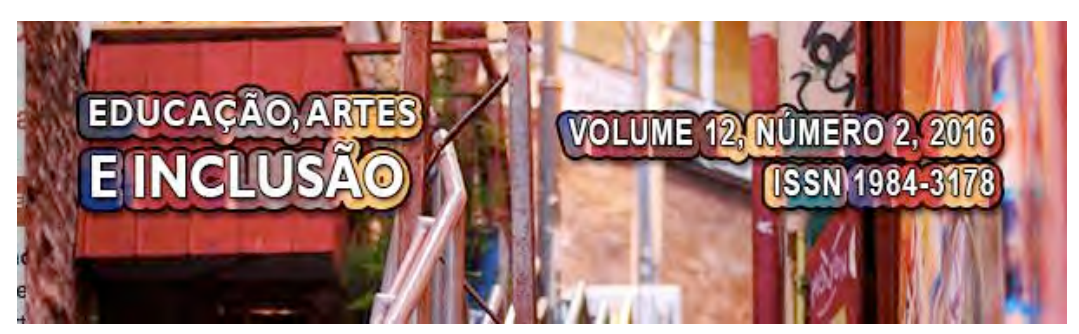

As classes dirigentes dominam como produtores e pensadores de ideias usando diferentes e diversos meios para difundir suas ideologias, a saber: família, igreja, partidos políticos, escolas, meios de comunicação, entre outros, fazendo com que interesses particulares tornem-se universais. Nas palavras de Kellner,

a ideologia, portanto, representa o mundo às avessas: o que é cultural e historicamente contingente aparece como natural e eterno; os interesses particulares de uma classe aparecem como universais; as imagens, os mitos e as narrativas eminentemente políticas aparecem como apolíticas (2001, p.147).

contudo, segue-se com as análises das ideologias neoliberais presentes em filmes estadunidenses de grande sucesso, são eles: Escritores da Liberdade e Professora Sem Classe. Inicialmente, far-se-á uma síntese do enredo dos filmes para, depois, passar a seleção de cenas/situações importantes, as quais expressam essas ideologias e à análise das cenas no enredo utilizando referencias teóricos para tal,

embora a desmistificação faça parte da crítica da ideologia, expor simplesmente a dominação não basta; precisamos olhar por trás da superfície ideológica para ver as forças e as lutas sociais e históricas que geram discursos ideológicos e examinar o aparato e as estratégias cinematográficas que tornam atraentes as ideologias. (...) A critica da ideologia não é apenas denunciadora e deve procurar momentos de crítica social e de contestação em todos os textos ideológicos, inclusive nos conservadores, (KELLNER, 2001, p. 143).

\subsection{ESCRITORES DA LIBERDADE}

Escritores da Liberdade com título na língua inglesa Freedom Writers, foi lançado no ano de 2007, produzido pela Paramount Pictures. O filme baseia-se do Best seler: O diário dos escritores da liberdade. O filme é estrelado por Hilary Swank (premiada com Oscar em Garotos não Choram e Globo de Ouro em Menina de Ouro). Participam também do elenco: Imelda Stauton, Patrick Dempsey e Scott Glenn. É dirigido por Richard LaGravenese e produzido na Alemanha e nos Estados Unidos. A classificação indicativa do filme é livre e o gênero é drama ${ }^{1}$.

\footnotetext{
1 Dados disponíveis na: http://www.interfilmes.com/filme 16856 escritores.da.liberdade.html. Acesso em 14/07/2012.
} 


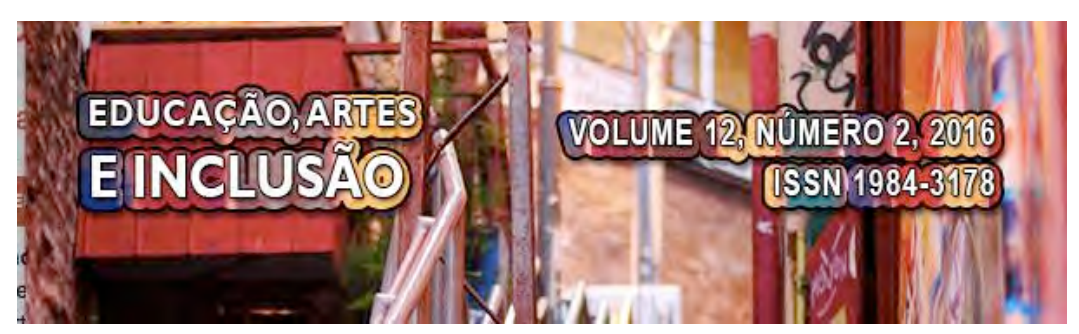

O filme retrata a história de uma professora recém "formada": Erin Gruwell, representada por Hilary Swank, que começa a lecionar numa escola de periferia, na qual pouco se aposta nos alunos, em especial na turma que é posta como docente. Há expectativa de desistência e fracasso escolar, diante da sórdida realidade vivida pelos alunos, marcada pela vivência de situações diversas de violência no cotidiano e assédios do mundo do crime.

A professora Gruwell inicia seu trabalho e se depara com alunos pouco interessados, mas aos poucos vai conseguido conquistar a classe por meio de recompensas, tais como: passeios, jantares e doação de livros literários. Ela incentiva a leitura de clássicos da literatura, mas como a gestão da escola não autoriza que os alunos leiam os livros para não os estragarem e/ou por pensarem que os alunos não os entenderão, ela começa a comprar um exemplar para cada aluno. Mas, o salário que recebe não é suficiente para custear todos os gastos com as ditas recompensas aos alunos, então ela passa a trabalhar também em uma loja e em um hotel. Assim fica menos tempo em casa e o relacionamento com o marido vai se desgastando cada vez mais, até que seu cônjuge sai de casa e separam-se.

Mesmo com tudo isso, a professora não desiste de realizar seus sonhos, pensando que é jovem e está no momento certo para buscar a realização profissional. Os alunos com o passar do tempo interessam-se mais pela leitura e obtém progressos satisfatórios, inclusive alcançando boas notas no exame de avaliação nacional dos Estados Unidos. Eles passam a escrever suas histórias e a lutar pelos seus objetos, inclusive fazem atividades para arrecadar dinheiro para que a senhora que acolheu Ane Frankie os visite. Assim como, conseguem que a senhora Gruwell continue sua professora no ano seguinte o que contrariava o regimento escolar.

O protagonismo da professora e condição de colocar-se como principal responsável pelo sucesso escolar de seus alunos é incentivado pela ofensiva neoliberal. Nas palavras de Shiroma: "o ideário da reforma educacional atribui ao professor um protagonismo fundamental. Paradoxalmente, nele identifica a responsabilidade pelas mazelas do sistema público e o mágico poder de extirpá-las” (2007, p. 82).

Os ideais neoliberais depositam na figura do professor responsabilidades que não são essencialmente dele, mas do Estado a quem caberia a responsabilidade de manter uma educação de qualidade a todos, como direito dos cidadãos e não dependendo da boa fé de seus 


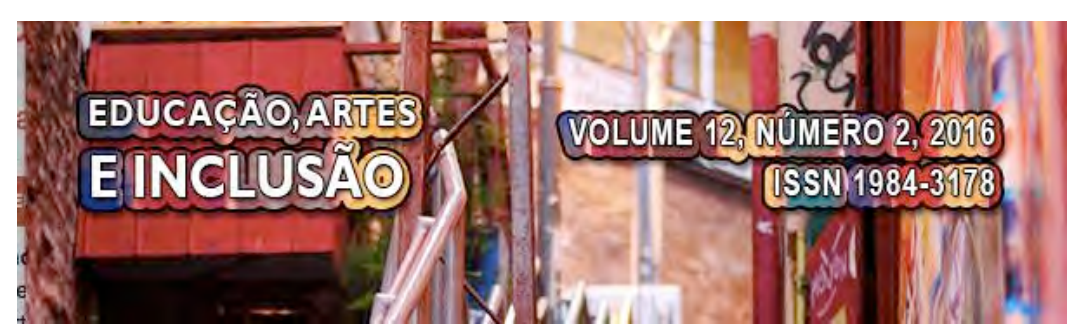

profissionais em auxiliar no custeio da educação. A mesma autora continua: "o professor, tido como agente de mudança, é o responsável pela realização do ideário do século XXI. Suas principais características seriam competência, profissionalismo, devotamento, (...) empatia, autoridade, paciência e humildade. Um professor edificante enfim”. Ainda recomenda- se que “o professor exerça outras profissões além da sua, a de ser professor” (SHIROMA, p. 58).

Em Escritores da Liberdade destacam-se duas situações:

- A cena em que a professora, ao conversar com a coordenadora pedagógica a qual relata a evasão dos alunos e a professora afirma: "Se eu fizer meu trabalho talvez eles não desistam".

O professor precisa comprometer-se com o processo de ensino-aprendizagem, mas há outras variáveis históricas, econômicas, sociais e políticas que interferem no processo de ensino e podem colaborar para a evasão. O professor não tem super poderes para evitá-las. Com essa fala e com suas atitudes, fica evidente que os sujeitos são os únicos responsáveis pelo seu sucesso e/ou fracasso. De acordo com Gentili, para a ofensiva neoliberal a grande maioria dos sujeitos é responsável por seu destino através do mérito e do esforço. Perante essa lógica se a escola funciona mal é porque:

as pessoas não reconhecem o valor do conhecimento e investem pouco em seu "capital humano"; os professores trabalham mal e não se atualizam; os alunos fazem de conta que estudam, quando, em realidade, perdem tempo, etc. a sociedade não apenas sofre a crise da educação. Ela também a produz e a reproduz. (Gentili, 2001, p.22)

Essa história é posta como um exemplo de atuação docente e dedicação ao trabalho, inclusive deixando-se de lado a vida pessoal do profissional professor. E, principalmente, o colocando como responsável financeiro por sua atuação, o que vem ao encontro do ideário neoliberal que desresponsabiliza o Estado em relação a recursos para educação.

Assim, cabe aos sujeitos conforme sua dedicação e esforços sobrepujarem quaisquer dificuldades, tendo como primeiro passo o reconhecimento de que 


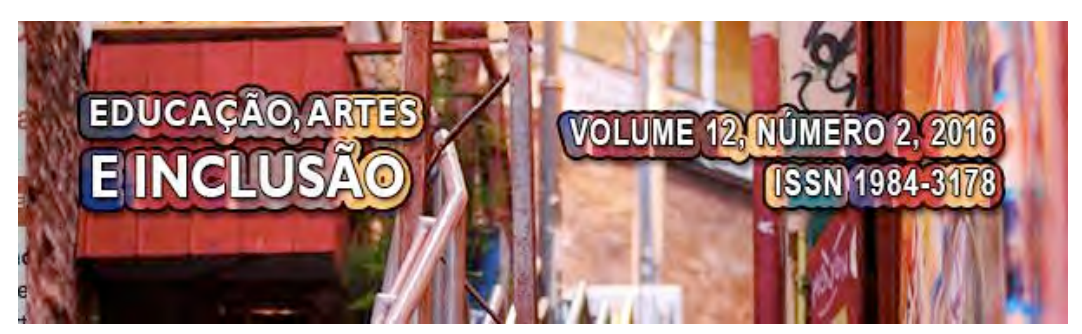

No início o filme mostra cenas de rotinas tradicionais de escola, no entanto, retrata a história de uma professora com atitudes nada convencionais, a saber: fala palavrões, desrespeita alunos, aceita propina de pais e é desonesta. A professora Elizabeth é vivida por Cameron Diaz, que havia trabalhado durante um ano em uma escola sem envolver-se. Ela tinha apenas um número pequeno de aulas, pois estava se preparando para casar com um homem bonito e milionário, o qual a sustentava. Esse noivo sob a orientação da mãe, desistiu do casamento por desconfiar do amor dela. Assim, ela vê-se obrigada a continuar a lecionar para sobreviver. E assim o faz. Suas aulas restringem-se a passar filmes a seus alunos e, mesmo quando questionada sobre isso por colegas, direção e pais ela apresenta justificativas para o que chama método de ensino com filmes, referindo-se aos filmes como os novos livros didáticos.

Seu principal objetivo é conseguir um novo casamento. Para encantar um colega rico resolve colocar silicone nos seios. Para tal tarefa precisa conseguir dinheiro para o tratamento estético. Ao saber, que com o trabalho voluntário de lavagens de carro, professores e alunos conseguiam cerca de seis mil dólares; resolve participar desse trabalho como voluntária para conseguir desviar dinheiro para as próteses de silicone. Nas lavagens de carros mostra-se nada convencional com roupas muito insinuantes e consegue ter lucro ficando com parte do dinheiro. Como também aceita de pais propina para dar atendimento individual aos filhos.

A professora Elizabeth descobre que o professor que a turma conseguir alcançar a maior nota da escola na avaliação nacional receberá um bônus em dinheiro. Assim, desejosa de tal bônus começa a lecionar e utilizar métodos nada convencionais para que os alunos consigam êxito, mas ao fazer avaliações preliminares constata que os alunos não se apropriaram dos conhecimentos necessários à avaliação e procura através de meio ilícito obter o gabarito da prova. Seus alunos conseguem êxito na avaliação, ela é premiada com o bônus e consegue o dinheiro para a colocação das próteses tão necessária para seus planos de conseguir um marido rico.

Aos poucos, passa a interessar-se pelo bem-estar dos alunos. Mesmo tendo conseguido o dinheiro para as próteses de silicone, desiste do implante e também de ficar com o colega rico. Ela decide namorar um colega empobrecido (professor de educação física). Ao final do filme, Elizabeth consegue vingar-se se uma colega rival que no decorrer do filme sempre procura prejudicá-la. Assim como é supostamente promovida como orientadora escolar. 


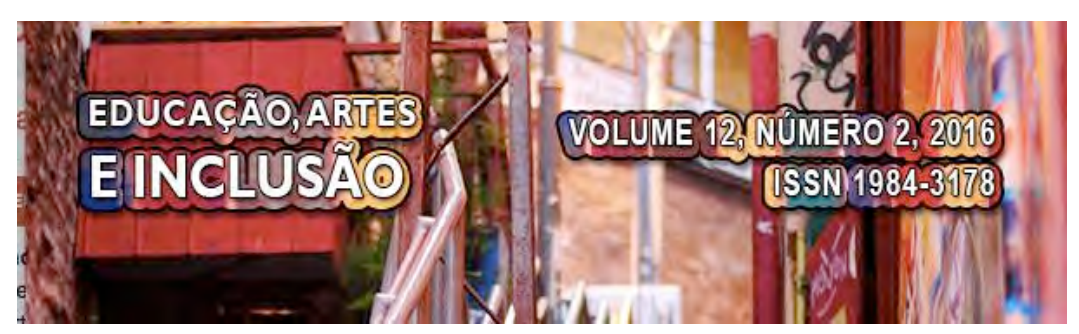

Os momentos destacados nesse filme são os seguintes:

- A cena em que Elizabeth resolve participar do projeto para a lavagem de carros e assim o faz no sábado, auxiliando na lavagem de veículos para arrecadar recursos financeiros à escola.

Percebe-se a importância atribuída ao voluntariado na educação para a ofensiva neoliberal. Deste modo o Estado desobriga-se com a educação, deixando que os muitos problemas educacionais sejam resolvidos pela comunidade organizada, voluntários e professores, responsáveis pelo sucesso ou fracasso da educação escolar.

$\mathrm{Na}$ história recente brasileira, a mídia, em especial a Rede Globo, incentivou o voluntariado na educação formal em sintonia com o ideário neoliberal, com o Projeto "Amigos da Escola".

Nesta perspectiva neoliberal a participação da comunidade é requisitada, mas não no sentido decisório em assuntos como o currículo, normas escolares, projetos pedagógicos, entre outros. Mas apenas como colaboração:

Participa-se desde que as regras sejam aceitas passivamente; caso contrário se "desestabiliza" a democracia. Naturalmente, em tais condições, a participação não é outra coisa senão um ardil, um ato hipócrita de simulação, destinado a legitimar decisões tomadas por outros (outras) e que nunca entram na pauta de discussão", conforme Gentili, (2001, p. 67).

- O momento em que ela descobre que o professor o qual tiver alunos com maiores notas no exame nacional receberá um bônus em dinheiro e isso modifica sua prática pedagógica, passando a interessar-se pela aprendizagem dos alunos.

Para a melhoria da qualidade da educação conforme o discurso neoliberal é importante instaurar o princípio da competição. Nas palavras de Gentili, esse "deve regular o sistema escolar enquanto mercado educacional" (2001, p. 23). Nesse sentido, a educação deixa de ser um direito dos cidadãos para ser uma mercadoria. A lógica mercadológica incentiva a competição para que os melhores triunfem, numa perspectiva meritocrática. 


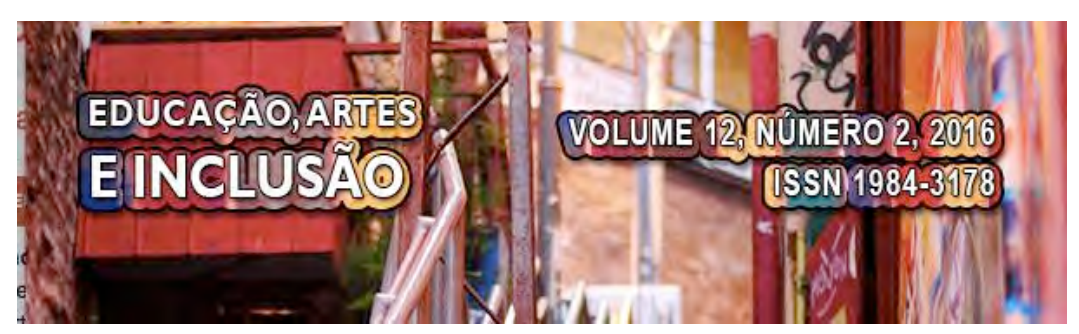

A professora Elizabeth modifica consideravelmente sua prática pedagógica pretendendo receber o bônus. Fica evidente no nesse filme que a supervisão da direção da escola em sua prática pedagógica e a cobrança dos pais não foram suficientes para que Elizabeth modificasse sua prática. O que foi decisivo para tal mudança foi a possibilidade de receber um recurso financeiro (bônus). Para Shiroma, a ideologia neoliberal pretende "convencer o professor a envolver-se nas reformas do sistema, a ter confiança nas inovações e, sobretudo, nas vantagens em aderir às medidas que assegurem possíveis mecanismos de recompensa aos que obtiverem melhores resultados entre os alunos" (2007, p. 59).

Os ajustes neoliberais, conforme Shiroma visavam "reformas administrativas que operassem uma transmutação do Estado administrador e provedor para um Estado avaliador, incentivador e gerador de políticas" (2007, p. 55). É importante salientar que a tendência é descentralização e centralização: descentraliza-se atribuindo autonomia às escolas para definição de programas e currículo e centraliza-se por meio de realização de avaliação nos diversos níveis, inclusive nacionais. Nas palavras de Gentili, “centralização do controle pedagógico (em nível curricular, de avaliação do sistema e de formação de docentes) e descentralização dos mecanismos de financiamento e gestão do sistema", (2001, p. 25). Assim, o Estado garante na legislação a autonomia dos estabelecimentos de ensino, mas os controla por meio de programas de avaliação nacionais, os quais também contribuem para a instauração do princípio da competição entre sujeitos, estabelecimentos escolares e sistemas de ensino.

\section{CONSIDERAÇÕES}

A mídia pode influenciar comportamentos em algumas situações, revelando assim sua capacidade de agendar e dirigir reações e estímulos, inclusive ao criar nos destinatários sentimentos de raiva, histeria, indignação (CITELLI, 2004). No entanto, não pode se afirmar que as pessoas são manipuladas pela mídia, os sujeitos não são receptores passivos do que ouvem, veem e leem na mídia; pois a interpretação do que está posto nos meios de comunicação de massa depende de ajustes discursivos mais amplos e da história de vida dos 


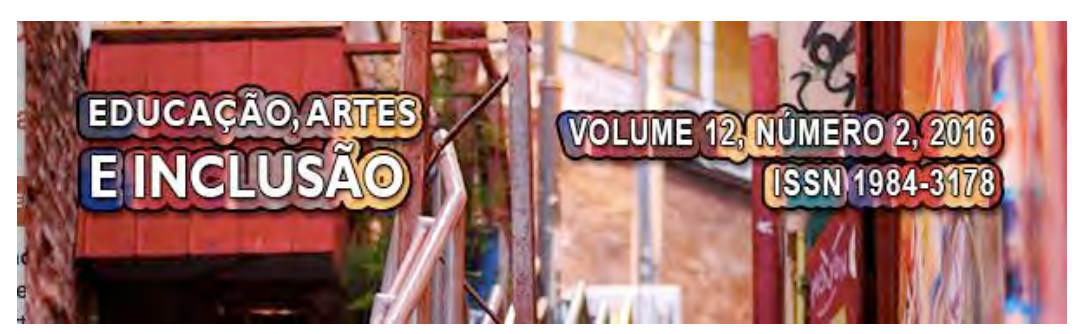

sujeitos, de condições de acesso a diferentes meios para informação, dos valores do sujeito, das condições históricas, econômicas e sociais do indivíduo. Conforme Marx e Engels,

A produção de idéias, de representações e da consciência está em primeiro lugar direta e intimamente ligada à atividade material (...) é a linguagem da vida real. As representações, o pensamento, o comércio intelectual dos homens surge aqui como emanação direta do seu comportamento material. $\mathrm{O}$ mesmo acontece com a produção intelectual quando esta se apresenta na linguagem das leis, política, moral, religião, metafísica, etc., de um povo. (...) .Contrariamente à filosofia alemã, que desce do céu para a terra, aqui parte-se da terra para atingir o céu (...); parte-se dos homens, da sua atividade real. É a partir do seu processo de vida real que se representa o desenvolvimento dos reflexos e das repercussões ideológicas deste processo vital. (...) Não é a consciência que determina a vida, mas sim a vida que determina a consciência, (1998, p.51-52)

Isto posto, é preciso considerar que a dominação exercida de uma classe sobre a outra também é uma dominação ideológica e os meios de comunicação são ferramentas para a articulação de ideologias dominantes para que as mesmas se tornem hegemônicas e colaborem para a manutenção do status quo. Nesse sentido, as análises realizadas caminharam, procurando desvelar as ideologias escolanovistas e neoliberais na educação presentes em filmes estadunidenses. Assim como refletir sobre elas, questioná-las, problematizá-las, buscando um olhar crítico e voltado aos interesses das classes trabalhadoras.

Após as análises, constatou-se que as ideologias escolanovistas e neoliberais estão muito presentes nesses filmes. Nos produtos analisados foram encontradas inúmeras ideologias, mas optou-se por citar apenas as mais salientes. Algumas delas estão presentes em todos os filmes analisados, dentre as quais se destaca: competitividade, mecanismos de avaliações nacionais e desresponsabilização financeira do Estado.

A instauração do princípio de competição aparece em todos os filmes de diferentes formas. No filme Escritores da Liberdade a competição ocorre entre professores que disputam para ver quem tem direito de lecionar para as turmas de terceiros anos. Já no filme Professore Sem Classe a competição ocorre também entre docentes, mas por outros 


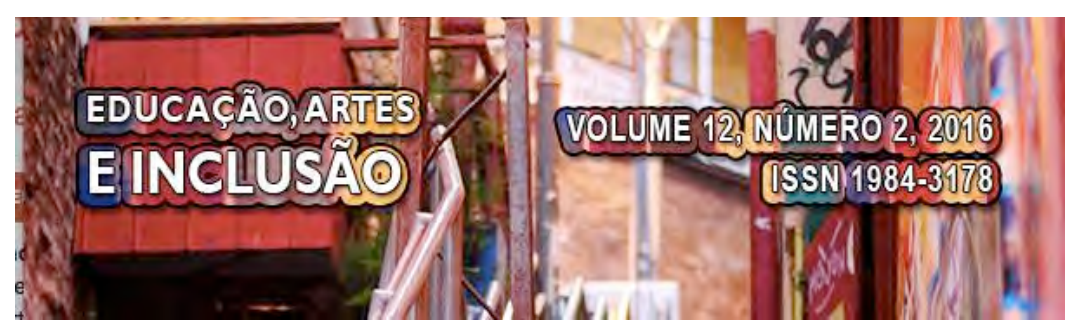

motivos: rivalidades pessoais, interesses amorosos e, em especial, para receber o prêmio de melhor turma por meio de avaliação externa.

A avaliação externa para aferir qualidade aparece em dois dos filmes selecionados: Professora Sem Classe e Escritores da Liberdade. No primeiro aparece como um divisor de mares na atuação profissional da docente, que, ao saber do prêmio modifica positivamente sua prática. Mas, mesmo assim mostra a fragilidade das avaliações, deixando evasivo se foi burlada ou não a avaliação. No filme Escritores da Liberdade a avaliação aparece como mecanismo de exaltação dos alunos excluídos e desfavorecidos economicamente, colaborando também para o resgate da auto-estima dos mesmos.

O "Estado Mínimo" é uma das mais importantes bandeiras neoliberais e essa ideologia está em todos os filmes analisados, aparecendo com a desresponsabilização financeira do Estado e a atuação de voluntários para ocupar o seu lugar de mantenedor.

A questão do voluntariado para ocupar a responsabilidade financeira do Estado aparece no filme Professora Sem Classe, na situação em que para a arrecadação de recursos discentes e docentes lavam carros da comunidade em um sábado. No filme Escritores da Liberdade a professora custeia, com mais dois empregos, os recursos e materiais que julga necessários para o bom desenvolvimento de sua prática pedagógica, desde livros literários até passeios e jantares.

Contudo, verifica-se que as ideologias neoliberais em relação à educação estão presentes no cinema estadunidense. Em suma, a ofensiva neoliberal pretende negar a educação como direito do cidadão, colocando-a como mercadoria. Nessa lógica despolitiza a educação e a despublicita, pois, ao tirá-lo do horizonte do direito o Estado não precisa responsabilizar-se financeiramente com ela. Na perspectiva mercadológica a competição fará com que os melhores triunfem o mesmo ocorrendo com discentes, docentes e escolas. $O$ fracasso é posto como responsabilidade dos sujeitos sem vinculação com outros fatores, enfatizando a meritocracia. $E$ os interesses das classes trabalhadoras em direção a uma escola de qualidade social, que 
